\title{
A Student-Driven Approach to Teaching Business Courses
}

\author{
Qiong Shao \\ Management School \\ Wuhan University of Science and Technology \\ Wuhan, China \\ 39682384@qq.com
}

\author{
Fang Wang \\ Management School \\ Wuhan University of Science and Technology \\ Wuhan, China \\ 57095788@qq.com
}

\begin{abstract}
This paper describes an approach to teaching business courses using bilingual languages at a bachelor level that is entirely coursework assessed. The approach involves students giving presentations of material they have researched based on fairly detailed subject guidance provided by the lecturer. The approach uses student-driven approach for the structuring of the content and the process through which learning takes place. The way in which subject material is presented to the students, and the learning cycle which takes place are described. Students develop presentation material in response to stories, which set the context and problems, and tasks which set the detailed areas for investigation. These presentations are done for small groups and the tutor is immediately commented on, leading to the revision of presentation material to appear in an assessed portfolio. The agile approach leads to the discovery of new ideas and frameworks by students, and to the development of skills in critically a nalyzing concepts.
\end{abstract}

Keywords-student-driven;agile approach; reflective cycle of learning; business course

\section{INTRODUCTION}

The teaching of business courses using bilingual languages is a challenging undertaking, not least due to the complexity of the subject area. These difficulties in delivering business courses may be compounded if the classes are large, as is often the case in offerings in the university. Lecturing styles which feed information to students in packages presented from the front of the class by the tutor may be inadequate for students working in small groups [1]. The lack of student involvement which is a property of lecture-based delivery does not encourage student learning. Lectures may be singularly inappropriate for teaching a volatile business subject. Student participation may require at the least case studies which are critically analyzed. Optimally, the students should be actively researching the area, critically appraising latest frameworks and learning by sharing their discoveries with their peers in a classroom situation [2].

Such a combination of large classes and volatile, ill-defined material calls for a different approach to teaching which is flexible while still establishing some foundations for arranging the material and organizing the learning experience. In teaching approach as is seen the shift from waterfall lifecycle development methods to agile development methods.

This paper describes an agile approach applied to business courses, explains the syllabus and the transformation of the syllabus into guidance for student delivery, and discusses the role of the student and teacher in delivering the courses.

\section{STUDENT-DRIVEN APPROACH}

\section{A. The Business Courses}

For a business course runs twelve weeks. Students are issued with a handbook which describes the course philosophy and conduct and splits the syllabus into ten sections. In each section the student is presented with a number of stories, with a list of tasks accompanying each story. The stories set the scene by describing a problem or case study. The tasks indicate what information and study is required to satisfy the needs of the story. Students are split into tutorial groups of four to six. Each week the students divide up the stories between them; each student tackling one story. If there are more students than stories, the group, in consultation with the tutor, will decide which stories to drop. If there are less stories than group members, students share a story and agree how to split up the tasks between them. Each student then uses some or all of the tasks as a basis for developing a 15-20 minute PowerPoint presentation.

The first week is introductory. The tutor explains the course philosophy and conduct, establishes groups and timetables, and outlines the first set of stories. Students then have a week to prepare their presentations. Teaching time is split into separate tutorial sessions for each group of an hour to an hour and a half. In each tutorial session students take turns to present their material in a conference or seminar environment. Students listen to each other's presentations, take notes and ask questions. The tutor clarifies issues and makes suggestions for improvement. The presenting student takes notes during the questioning and consultation that will

Sponsored by teaching innovation project of WUST (No. 2013Z033) 
enable her to revise and improve the presentation before incorporating it into her course portfolio. At the end of each tutorial the tutor explains and clarifies the next set of stories for the subsequent week's presentations. The tutor may make suggestions as to where to start in researching the tasks and may suggest key references or sources as a starting point. Students are encouraged to search the Internet for sources and to draw sources from academic journals as well as using textbooks where relevant. They are also encouraged to examine sources critically and to roam widely in their search for relevant information to fulfill the tasks.

Figure 1 illustrates the learning process in the course in which cycles of reflection occurs, developing the students understanding of the course subjects and their critical and research skills. While the principal cycle of reflection depends on tutor feedback on students' presentation. Students are required to reflect on their selection of stories and tasks, their selection of sources to support the tasks and their synthesis and presentation of material.

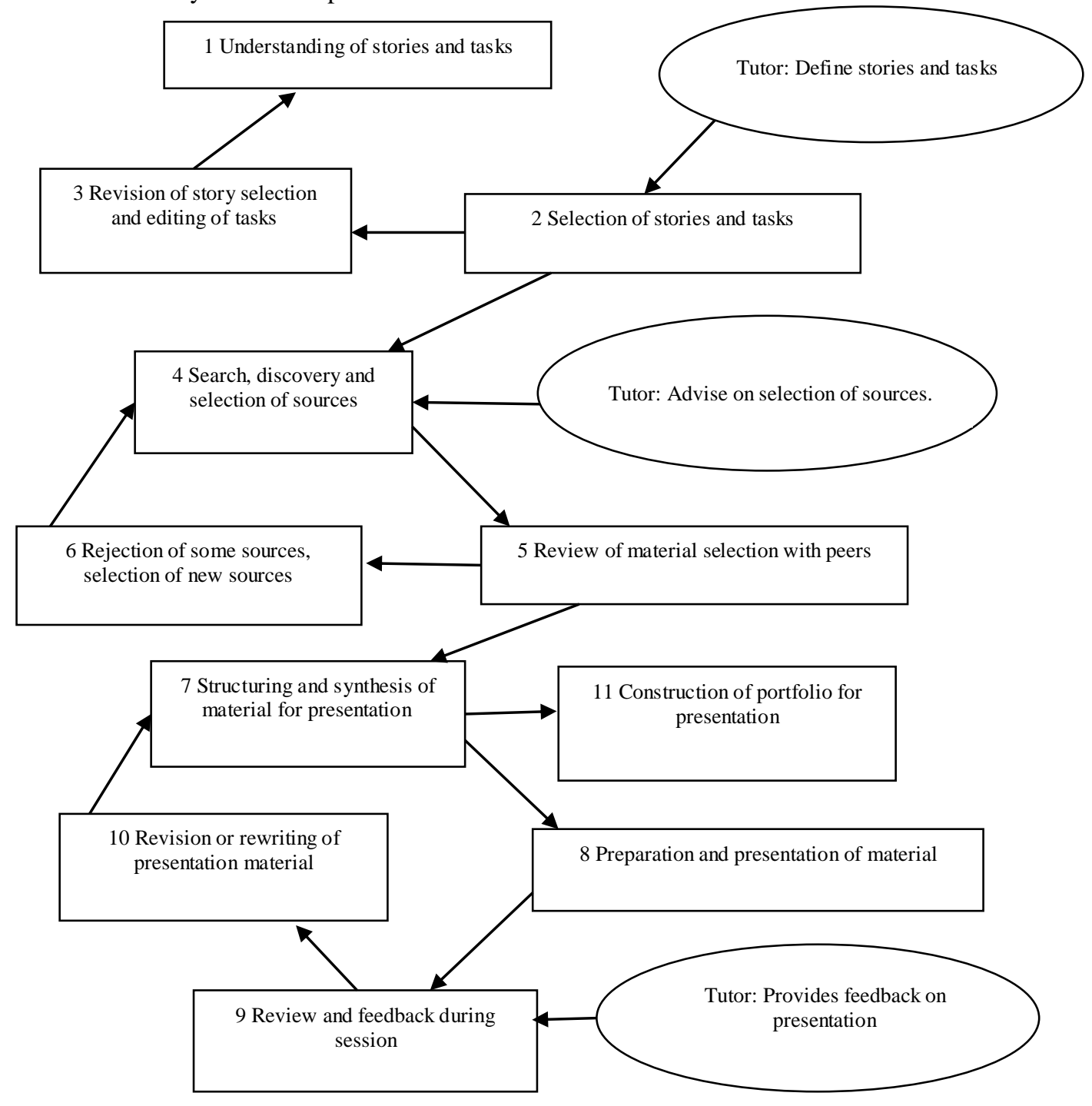

Figure 1 Student-Centered Cycles of Learning

The prime assessment vehicle is the course portfolio which consists of the ten presentations, with explanatory notes. These presentations should exhibit signs of revision in the light of comments from both the tutor and students during presentation. Hence the presentation is a key element in the learning process. An additional element of assessment involves the developing of a case study using a real organization in which concepts from the course are applied to develop business ideas for the organization and advice on their implementation.

\section{B. Syllabus Development}

The syllabus was developed with both a context and process in mind. Since the business courses are part of an international business administration bachelor degree, it fits in well to consider organizations where business functions and activities may be 
distributed geographically and are united in a virtual organization through the use of information technology. Another approach is also to consider where several organizations co-operate to meet the needs of a client and fulfill those needs by creating a virtual organization which communicates across the web to carry out contractual work, to manage the contract and to co-ordinate shared business functions. The process in which the syllabus is embedded involves the development and implementation of a business application. The following learning objectives were set for the course. The student will be able to:

- Critically analyze organizational information.

- Produce a business model and supporting business case for application implementation.

- Define requirements for application.

- Map requirements to available packages and services and critically evaluate potential business.

Opportunities are provided for the student to use diagrams, investigate real examples in business from their experience or from case studies on the Internet and to develop skills through explaining in their presentations.

\section{Developing Stories and tasks}

The syllabus was converted into a series of stories which set the scene and cover the syllabus. Some stories set the scene for an academic concept. The story paints a broad brush picture of the business area. Tasks are then defined which give detailed and concrete information and study requirements. The course handbook splits the syllabus into ten sessions, defining two to six stories and their related tasks for each session. There is a balance of case studies and factual tasks. The tasks are carefully written to ensure that the student needs to employ critical thinking and creativity to fulfill the tasks. Students are encouraged to reflect on the sources and material they find and present their own insights and ideas. It would easily be possible to add new stories around different business situations, different viewpoints or student concerns. Hence students should be encouraged as part of the negotiation process to suggest other areas of study and key subject areas.

\section{THE STUDENT'S ROLE}

The student is the developer and deliverer of subject material under the tutor's guidance. This involves developing and presenting material based on the tasks associated with a particular story. The student must understand the questions; have some idea of where to pursue relevant material; arrange, edit and synthesize material in a coherent way; present the material in a workshop environment; answer questions about the material; reflect on concepts discussed in the presentation sessions; and critically revise their work to form the final portfolio. Such a range of activities develops skills in researching, presentation, listening and revising in addition to the knowledge an understanding of business ideas.

Developing and presenting material on a weekly basis in a twelve week course is a demanding task which helps develop time management skills. Resources are drawn from web-sites, journals and textbooks. Students may use a textbook as a starting point for understanding the basic concepts. The student needs to develop a critical eye and the ability to focus on a few key references and sources which will support the tasks. The student must neither do a superficial job in researching the tasks nor get so bogged down in pursuing references

The students also need to develop the skills concerned with working in teams. Since students form teams, team work is required in dividing up the material. Although students work individually on their tasks and stories and present individually within a team session, in good teams the students support each other by shedding light on other team members' tasks outside the presentation session and during presentation. A student researching her task may find a source relevant to another student's tasks and share that with her.

Students often talk through their presentations which each other before the presentation session. During the session, students ask each other supportive questions, help each other with questions and use the detailed knowledge they acquire of their own tasks to enlighten other students' tasks and to identify links and commonality. Such activities are a key ingredient of the learning experience. In order to gain a rounded learning experience, each student is expected to listen to the other students presentations, to take notes and to ask questions. In a team atmosphere, significant learning will take place as a result of students interacting with other students' presentations.

\section{THE TUTOR'S ROLE}

The tutor is director of studies, high priest of the subject area, counselor, mentor, reviewer and assessor rolled into one [3]. The tutor may write the stories and tasks or use the ones provided in the course handbook. Either way, the tutor must have intimate knowledge of the subject area. The tutor will have to guide the students' research, critically evaluate the material presented, fill in missing material and direct students to references and sources that will enable them to produce a complete, comprehensive and rounded product for the portfolio; mediate student discussions during the presentations and fill in any gaps between presentations to assure that the entire subject area as defined in the syllabus is addressed. Filling in gaps will primarily involve pointing out the unifying conceptual links between presentations. This requires deep knowledge on the tutor's part as the tutor is acting as the expert 
consultant. The tutor is not only supporting the learning of the business subject area, but is also tutoring at the meta-level in teaching the students a variety of research skills.

The tutor will provide guidance on what Internet and journal sources may be relevant [4]. She will teach how to search a journal, examine titles and abstracts for relevancy and read the text of a paper in an efficient way in order to extract key concepts of relevance to the presentation. She will encourage and teach a critical approach to Internet sources. How authority is the sou rce? How does it relate to commercial interests? How do we assess the value of a web site as a source of real life case study material, a source of key concepts, or a survey of current coverage of business? Presentation skills in using PowerPoint slides, developing good presentations and physical presentation style will also be developed in the course of the presentation sessions.

The critical review which occur on-the-spot during the presentations is a key element of the learning process and the reflective cycle [5]. Students may or may not be interrupted during their presentations according to their preference. But at the end of the presentation, students ask questions and then the tutor comments on the presentation. This immediate feedback encourages critical reflection about the material. It will involve commenting on new avenues the student could explore; corrections to be made to material which is wrong, additional slides which may be needed for completeness, clarifications required, and elaboration where the material is too terse and explanations are missing. The students will revise their presentations and extend notes accompanying presentations as a result of this instant tutor feedback. Instant feedback improved learning and the results of this critical reflection could be observed in the final portfolio. This process makes for hard work for the tutor who must listen hard to the whole presentation. Such listening is a key skill the tutor must develop in order to effectively interpret student work and advise on portfolio improvements.

The tutor will require around 20 minutes per student each week to listen to the presentation, ask questions and review the slides. Tutorial should contain 5-6 students. Student groups could present concurrently, grouped round PCs, and the tutor may then tour around groups. Alternatively, students could be randomly selected to speak such that not every student speaks every week. Another approach could involve a goldfish bowl technique where students in an inner circle take turns to present extracts of their talks, watched by more students in an outer circle.

The assessment role will involve marking the portfolio with sensitivity to what changes have been made and to what extent the student has entered the reflective process, as well as marking the case study work with attention to how the course, or particular areas of the course, have been applied to a real-world situation.

\section{EVALUATION}

A student-driven approach, as described in this paper, gives the students the confidence to learn on their own. Students found the course challenging and interesting, although it was seen as a hard course involving a lot of work. Through carrying out their own research and doing presentations a sense of ownership of the material was achieved which resulted in some deep learning. The cycle of reflection encouraged by instant feedback during presentations led to the development of critical analysis and research skills and, for many students, a steady improvement in presentation quality over the twelve weeks. There was significant value in working in teams. Some teams took on their own particular characteristics as students shared understanding and encouraged each other. Students provided each other with support which may have reduced the drop-out rate. Student discussion of presentations, while sometimes needing to be encouraged by the tutor, occurred throughout all sessions and provided an additional source of feedback above and beyond the tutor's feedback. Reflection and rewriting of the material added to the learning experience and was reflected in marks which were, on average, higher than those of other courses. Tutor involvement is critical to the success of such a teaching approach. Feedback, as well as directing studies and acting as the user who defines what the stories are and enters into negotiation as to which tasks should be delivered are all essential parts of the tutor's role.

\section{REFERENCES}

[1] M. Ananyeva, A Learning Curriculum: Toward Student-Driven Pedagogy in the Context of Adult English for Academic Purposes, English for Specific Purposes, and Workplace English Programs, TESOL Journal, Vol. 5 (2014) 8-31.

[2] L. Beckert, T. Wilkinson, A needs-based study and examination skills course improves students' performance, Medical Education, Vol. 37(2013)424-428.

[3] G. Gareth. and B.Oates, Lecture-free Teaching of Systems Analysis: An Action Research Study. Proceedings of the Informing Science and Information Technology Joint Conference (2003) 24-27.

[4] K. Ian. Investigating Student's Beliefs about Their Preferred Roles as Learners, Educational Research, Vol. 46(2014) 301-312.

[5] C. Palermo, A. Chung, Evaluation of assessment in the context of work-based learning: Qualitative perspectives of new graduates, Nutrition \& Dietetics, Vol. 72(2015) 143-149. 